\title{
Concentrações salinas combinadas com tempos de hidratação: efeito no tempo de cocção em feijão
}

\author{
Salts concentrations in combination with soaking time: effect in bean cooking time \\ Juliano Garcia BERTOLDOํㅜ, Fabiani da ROCHA ${ }^{2}$, Leire Daiane BARILI², Naine Martins do VALE², \\ Jefferson Luís Meirelles COIMBRA ${ }^{2 *}$, Altamir Frederico GUIDOLIN ${ }^{2}$
}

\section{Resumo}

Este trabalho teve como objetivo investigar o efeito da adição de diferentes doses de $\mathrm{NaCl}$ na água de hidratação, durante diferentes tempos, buscando uma redução no tempo de cocção. O Brasil, embora seja considerado um grande produtor e um dos maiores consumidores de feijão, está reduzindo gradativamente o consumo. Sendo assim, é necessário dispor de técnicas que facilitem o preparo do feijão, podendo dessa forma reverter a tendência de consumo e como consequência incentivar a produção. O experimento foi conduzido na área experimental do Instituto de Melhoramento e Genética Molecular da UDESC - IMEGEM, em Lages - SC. Foram avaliados os efeitos de três concentrações de $\mathrm{NaCL}$ (0, 50 e 125 g.L $\left.\mathrm{L}^{-1}\right)$ em dois genótipos de feijão (Pérola e IPR Uirapuru) hidratados durante três tempos (0,5, 9 e 18 horas). Os resultados revelaram um efeito significativo das doses de $\mathrm{NaCl}$ na redução do tempo de cocção. A adição de 56,50 g. $\mathrm{L}^{-1}$ de $\mathrm{NaCl}$ foi suficiente para reduzir significativamente o tempo de cocção. A hidratação dos grãos de feijão propiciou a redução no tempo de cocção, sendo necessárias 12,5 horas para a máxima hidratação, independente dos genótipos avaliados.

Palavras-chave: Phaseolus vulgaris L.; tempo de cozimento; $\mathrm{NaCl}$.

\begin{abstract}
This study aimed to investigate the effect of adding different doses of $\mathrm{NaCl}$ in hydration water, during different times, in order to reduce cooking time. Although considered a major producer and one of the largest bean consumers, Brazil has been experiencing a gradual decrease in consumption. Therefore, it is necessary to facilitate the preparation of beans to increase its consumption and production. This study was conducted at the experimental area of the Institute of Molecular Genetics and Plant Breeding at UDESC - IMEGEM, in the city of Lages, SC-Brazil. We evaluated the effect of three doses of $\mathrm{NaCL}\left(0,50 \mathrm{e} 125 \mathrm{~g} \mathrm{~L}^{-1}\right)$ in two genotypes of beans (Pérola and IPR Uirapuru), hydrated at three different times $(0.5,9$, and 18 hours). The results revealed a significant effect of the $\mathrm{NaCl}$ doses on cooking time reduction. The addition of $56.50 \mathrm{~g} \mathrm{~L}^{-1}$ of $\mathrm{NaCl}$ is sufficient to significantly reduce the cooking time. The soaking of bean grains provided reduction in cooking time, and the maximum hydration was attained after 12.5 hours of soaking regardless of the genotype evaluated.
\end{abstract}

Keywords: Phaseolus vulgaris L.; cooking time; $\mathrm{NaCl}$.

\section{Introdução}

O Brasil é um grande produtor e consumidor de feijão, merecendo destaque no cenário mundial de cultivo dessa leguminosa. Entretanto, estão ocorrendo mudanças no padrão de consumo e produção, fato este denotado pela redução na produção e no consumo de feijão no Brasil. No ano de 1995, por exemplo, o consumo de feijão atingiu patamares de $18,9 \mathrm{~kg}$ per capita.ano $\mathrm{o}^{-1}$; atualmente, o consumo per capita.ano $^{-1}$ não é superior a $12 \mathrm{~kg}$. Nas grandes metrópoles brasileiras, este valor é ainda menor, cerca de 9,2 kg per capita.ano-1 de feijão, categorizando um decréscimo percentual, em relação a 1975, de $37 \%$ do consumo do feijão.

Essa redução do consumo de feijão vem ocorrendo nas últimas décadas em virtude de mudanças no cotidiano dos consumidores, com menor disponibilidade de tempo para o preparo da alimentação. Assim sendo, nos últimos anos verificou-se acentuada queda do consumo do produto feijão, sendo aos poucos substituído por alimentos de menores preços e de rápido preparo (FERREIRA; DEL PELOSO; FARIA, 2002).

Outro fato que colabora para o gradual declínio do feijão, é que, ao longo do tempo de armazenamento, o feijão perde qualidade nutricional e sensorial, sendo necessário um maior tempo para a cocção dos grãos (GARCIA; LAJOLO, 1994). Fato que induz a uma diminuição na entressafra, já que o consumidor tem preferência pelo produto recém-colhido.

O desenvolvimento de técnicas que facilitem o preparo do feijão podem contribuir para viabilizar o aumento no consumo e como consequência favorecer a produção. Por exemplo, Ialcim e Ersan (2003), avaliando genótipos de grão de bico, relataram que a embebição de sementes de grão-de-bico em água com

${ }^{1}$ Centro de Ciências Agrárias, Recursos Genéticos Vegetais, Universidade Federal de Santa Catarina - UFSC

2 Centro de Ciências Agroveterinárias, Instituto de Melhoramento e Genética Molecular, Universidade do Estado de Santa Catarina - UDESC, Av. Camões 2090, CEP 88520-000, Lages - SC, Brasil, E-mail: coimbrajefferson@cav.udesc.br

${ }^{*}$ A quem a correspondência deve ser enviada 
cloreto de sódio $(\mathrm{NaCl})$ por 16 horas propicia uma redução no tempo de cozimento.

Considerando a necessidade de reduzir o tempo para o preparo do feijão, este trabalho teve como objetivo investigar o efeito de adição de diferentes doses de $\mathrm{NaCl}$ na água de hidratação, durante diferentes tempos, buscando minimizar o tempo de cocção.

\section{Material e métodos}

O experimento foi conduzido na área experimental do Instituto de Melhoramento e Genética Molecular da UDESC (IMEGEM), em Lages - SC, situada a $27^{\circ} 47^{\prime} \mathrm{S}$ de latitude, $50^{\circ} 18^{\prime} \mathrm{W}$ de longitude e $900 \mathrm{~m}$ de altitude, na safra de 2006/07. A unidade experimental foi constituída por seis fileiras de $5 \times 3$ $\mathrm{m}$ de comprimento, espaçadas em 0,5 m, e com área útil de $15 \mathrm{~m}^{2}$ por parcela, em uma densidade de 200,000 plantas por hectare. O experimento foi conduzido sob o delineamento experimental de blocos ao acaso com três repetições.

As parcelas foram colhidas em Janeiro de 2007. Após a trilha mecânica, o feijão foi peneirado e as amostras de feijão foram levadas à estufa a $26^{\circ} \mathrm{C}$, em sacos de papel, onde permaneceram até que atingissem a umidade de $12 \%$. Após este procedimento, as amostras foram armazenadas em sacos de papel à temperatura e umidade ambientes durante sete meses.

Os fatores avaliados neste estudo foram: i) dois genótipos (Pérola e IPR Uirapuru); ii) três tempos de hidratação $(0,5,9$ e 18 horas) e; iii) três concentrações de $\mathrm{NaCl}\left(0,50\right.$ e 125 g.L $\left.\mathrm{L}^{-1}\right)$, ou seja, um experimento fatorial $2 \times 3 \times 3$, com duas repetições.

No preparo das amostras, foram pesadas as doses de $\mathrm{NaCl}$ $(0,10$ e $25 \mathrm{~g})$ correspondentes a cada tratamento, as quais foram dissolvidas em $200 \mathrm{~mL}$ de água destilada (constituindo as concentrações 0,50 e 125 g. $\mathrm{L}^{-1}$ ) e acrescidas de $50 \mathrm{~g}$ de feijão, permanecendo à temperatura de $25^{\circ} \mathrm{C}$, durante o respectivo tempo de hidratação. Após a hidratação, procedeu-se à análise do tempo de cozimento com o aparelho cozedor de Mattson, adaptado por Proctor e Watts (1987). O aparelho é composto por 25 hastes, as quais têm uma ponta de $1 \mathrm{~mm}$ de diâmetro que ficam apoiadas sobre os grãos de feijão. $\mathrm{O}$ aparelho com os 25 grãos é colocado em recipiente com água destilada fervente. Quando 13 hastes $(50 \%+1)$ perfurarem os grãos, considera-se a amostra cozida. A cocção foi realizada em agosto de 2007, ou seja, com amostras armazenadas durante 7 meses.

Os dados foram submetidos à análise de variância pelo teste $\mathrm{F}$, ao nível de $5 \%$ de probabilidade de erro, para testar as hipóteses dos efeitos principais e da interação entre os fatores. Quando o efeito da interação foi significativo, os graus de liberdade foram desdobrados através do efeito simples e posteriormente foram ajustadas regressões para as interações.

\section{Resultados e discussão}

Os valores das médias ajustadas para as variáveis dependentes, peso (g), volume ( $\mathrm{mL}$ ) e tempo de cocção (minuto) e as combinações entre os fatores experimentais, genótipos $(\mathrm{G})$, tempos de hidratação $(\mathrm{H})$ e concentrações de $\mathrm{NaCl}(\mathrm{S})$, estão apresentados na Tabela 1 .
Os resultados revelaram uma possível dependência de todas as variáveis experimentais com os fatores em estudo, como por exemplo, o aumento no tempo de hidratação promoveu a redução no tempo de cocção, e concentrações de $\mathrm{NaCl}$ promoveram uma redução no tempo de cocção.

Considerando o exposto acima, foi realizada a análise de variância pelo teste $\mathrm{F}$ ao nível de $5 \%$ de probabilidade de erro, no intuito de comparar as estimativas de variâncias. Os resultados da análise de variância dos fatores experimentais genótipos (G), tempos de hidratação $(\mathrm{H})$ e concentrações de $\mathrm{NaCl}(\mathrm{S})$ estão apresentados na Tabela 2 . Os resultados revelaram efeito significativo da interação tripla entre os fatores $\mathrm{G} \times \mathrm{H} \times \mathrm{S}$ para as variáveis resposta peso $(\mathrm{g})$ e volume $(\mathrm{mL})$. Por outro lado, os resultados para a variável tempo de cocção evidenciaram efeito significativo apenas para o tempo de hidratação e concentrações de $\mathrm{NaCl}$.

Assim sendo, foi necessário decompor os graus de liberdade da interação tripla significativa, através do efeito simples, fixando um fator e variando o outro (BERTOLDO et al., 2008). Deste modo, foram fixados os fatores genótipos $(\mathrm{G})$ e tempo de hidratação $(\mathrm{H})$ e variou-se o efeito do fator concentrações de $\mathrm{NaCl}(\mathrm{S})$, conforme representado na Tabela 3. Ainda, foi necessário determinar os graus dos polinômios para a interação tripla $(\mathrm{G} \times \mathrm{H} \times \mathrm{S})$ no sentido ajustar as equações de regressão de acordo com o grau significativo do polinômio, ou seja, linear ou quadrática (Tabela 3).

Os resultados evidenciaram comportamentos similares entre os genótipos nos tempos de hidratação vs concentrações de $\mathrm{NaCl}$ (Figura 1). De acordo com a Figura la e 1b, para a variável peso $(\mathrm{g})$, na medida em que se aumentam as concentrações de $\mathrm{NaCl}\left(\mathrm{g} . \mathrm{L}^{-1}\right)$, houve uma redução linear no peso dos grãos nos diferentes tempos de hidratação, com exceção do genótipo Pérola no tempo de hidratação 0,5 hora. Tal fato pode estar indicando que para este genótipo, tempos de hidratação superiores a 0,5 hora em condições salinas são significativos, não o sendo em períodos menores. Para o genótipo Pérola houve uma redução de 97,83 g (concentração 0 g. $\mathrm{L}^{-1}$ ) para 88,83 g (concentração 50 g.L $\mathrm{L}^{-1}$ ) e para 75,33 (concentração 125 g.L $\mathrm{L}^{-1}$ ) no peso (g) para o tempo de hidratação 9 horas. Com o tempo de hidratação de 18 horas para a concentração 0 g.L $\mathrm{L}^{-1}$ de $\mathrm{NaCl}$ o peso de grãos foi de 95,83 g; para a concentração 50 g. $\mathrm{L}^{-1}$ de $\mathrm{NaCl}$, a redução foi de 91,13 e $84,08 \mathrm{~g}$ para a concentração 125 g.L.-1. Para o genótipo IPR Uirapuru, também houve uma redução linear no peso para todos os tempos de hidratação avaliados. Sendo que, no tempo de hidratação de 0,5 hora, a redução foi de $62,93,59,63$ e 54,68 g para as concentrações 0,50 e 125 g. $\mathrm{L}^{-1}$, respectivamente. Ainda, foi observada uma redução de 93,75 (concentração 0 g.L $\mathrm{L}^{-1}$ ), 88,55 g (concentração 50 g.L $\mathrm{L}^{-1}$ ) e 80,75 g (concentração 125 g. $\mathrm{L}^{-1}$ ) para o tempo de hidratação de 9 horas. Em 18 horas de hidratação, pode ser verificada a redução significativa de 97,17, 91,67 e 83,42 g no peso, com as concentrações 0,50 e 125 g. $\mathrm{L}^{-1}$ de $\mathrm{NaCl}$, respectivamente. Tal resultado revela que o comportamento para o peso de grãos $(\mathrm{g})$ é similar em ambos os genótipos, nos tempos de hidratação e nas concentrações de $\mathrm{NaCl}$ estudados e que entre 0,5 e 18 horas de hidratação, o incremento no peso com o aumento das concentrações é reduzido. 
Tabela 1. Fatores experimentais genótipos $(G)$, concentrações de sal $(S)$ e tempo de hidratação $(H)$ em todas possíveis combinações $(G \times S \times H)$ e valores das médias ajustadas (Lsmeans) para as variáveis experimentais peso (g), volume (mL) e tempo de cocção (minutos).

\begin{tabular}{|c|c|c|c|c|c|c|c|c|}
\hline Genótipo & $\begin{array}{c}\text { Concentração de sal } \\
\left(\text { g.L } L^{-1}\right)\end{array}$ & $\begin{array}{c}\text { Tempo de hidratação } \\
\text { (horas) }\end{array}$ & $\begin{array}{l}\text { Peso } \\
(\mathrm{g})\end{array}$ & Desvio padrão & $\begin{array}{c}\text { Volume } \\
(\mathrm{mL})\end{array}$ & Desvio padrão & $\begin{array}{c}\text { Cocção } \\
\text { (minutos) }\end{array}$ & Desvio padrão \\
\hline Pérola & 0 & 0,5 & 55,48 & 0,86 & 194,50 & 0,70 & 79,50 & 6,36 \\
\hline Pérola & 50 & 0,5 & 54,15 & 2,10 & 191,00 & 2,82 & 80,50 & 0,70 \\
\hline Uirapuru & 0 & 0,5 & 63,16 & 0,19 & 184,50 & 3,53 & 68,50 & 0,70 \\
\hline Uirapuru & 50 & 0,5 & 59,24 & 0,41 & 188,00 & 2,82 & 55,50 & 3,53 \\
\hline Pérola & 50 & 9 & 88,28 & 0,41 & 153,50 & 0,70 & 44,00 & 9,89 \\
\hline Pérola & 125 & 9 & 75,32 & 4,93 & 174,00 & 1,41 & 47,50 & 3,53 \\
\hline Uirapuru & 0 & 9 & 95,00 & 0,93 & 143,00 & 1,41 & 46,00 & 18,38 \\
\hline Uirapuru & 50 & 9 & 86,40 & 3,66 & 156,00 & 1,41 & 38,50 & 0,70 \\
\hline Uirapuru & 125 & 9 & 81,37 & 1,28 & 170,00 & 7,07 & 34,00 & 5,65 \\
\hline Uirapuru & 0 & 18 & 98,57 & 1,38 & 130,50 & 0,70 & 50,50 & 0,70 \\
\hline Uirapuru & 50 & 18 & 89,26 & 1,03 & 146,50 & 2,12 & 35,50 & 6,363 \\
\hline Uirapuru & 125 & 18 & 84,17 & 3,15 & 156,50 & 2,12 & 45,50 & 12,02 \\
\hline
\end{tabular}

Tabela 2. Resumo da análise de variância os caracteres peso de grãos (g), volume ( $\mathrm{mL}$ ) e tempo de cocção (minutos), obtidos a partir de dois genótipos de feijão (Pérola e Uirapuru), três tempos de hidratação $\left(0,5,9\right.$ e 18 horas) e três concentrações de sal $\left(0,50\right.$ e 125 g.L $\left.L^{-1}\right)$.

\begin{tabular}{lcrcc}
\hline \multicolumn{1}{c}{ F.V. } & G.L. & \multicolumn{3}{c}{ Q.M. } \\
\cline { 3 - 5 } & & $\begin{array}{c}\text { Peso } \\
(\mathrm{g})\end{array}$ & $\begin{array}{c}\text { Volume } \\
(\mathrm{mL})\end{array}$ & $\begin{array}{c}\text { Cocção } \\
\text { (minutos) }\end{array}$ \\
\hline Genótipo (G) & 1 & $29,35^{*}$ & 1,36 & 650,25 \\
Hidratação (H) & 2 & $4180,45^{*}$ & $7788,77^{*}$ & $3973,36^{*}$ \\
Sal (S) & 2 & $448,62^{*}$ & $1303,36^{*}$ & $664,77^{*}$ \\
$\mathrm{G} \times \mathrm{H}$ & 2 & $18,79^{*}$ & $42,11^{*}$ & 34,75 \\
$\mathrm{G} \times \mathrm{S}$ & 2 & 1,73 & 14,19 & 114,33 \\
$\mathrm{H} \times \mathrm{S}$ & 4 & $44,38^{*}$ & $138,27^{*}$ & 212,44 \\
$\mathrm{G} \times \mathrm{H} \times \mathrm{S}$ & 4 & $17,48^{*}$ & $18,44^{*}$ & 219,83 \\
Erro & 17 & 4,40 & 5,77 & 185,66 \\
Total & 35 & - & - & - \\
$\mathrm{C} . \mathrm{V}$. & - & 2,68 & 1,46 & 24,61 \\
$\mathrm{R}^{2}$ & - & 0,99 & 0,99 & 0,79 \\
Média & - & 78,20 & 163,80 & 55,36 \\
\hline
\end{tabular}

*Significativo ao nível de $5 \%$ de probabilidade de erro pelo teste $\mathrm{F}$.

Comportamento oposto foi verificado para a variável volume $(\mathrm{mL})$, ocorrendo um aumento linear no volume $(\mathrm{mL})$. Para o genótipo Pérola, quanto para o genótipo IPR Uirapuru, o comportamento foi o mesmo (Figura 1c e 1d). Com exceção do genótipo Pérola no tempo de hidratação de 0,5 hora, todas as concentrações de $\mathrm{NaCl}$ e tempos de hidratação foram significativos. Sendo assim, para o genótipo Pérola, houve um incremento no volume (mL) em 140, 153,6 e $174 \mathrm{~mL}$, para as concentrações 0,50 e 125 g.L.- ${ }^{-1}$ de $\mathrm{NaCl}$, respectivamente, para o tempo de hidratação nove horas. Para o tempo de hidratação de 18 horas, o incremento foi de $132 \mathrm{~mL}$ para a concentrações 0 g.L $\mathrm{L}^{-1}, 140,3 \mathrm{~mL}$ para a concentração 50 g. $\mathrm{L}^{-1}$ e $152,75 \mathrm{~mL}$ para a concentração 125 g.L.- de NaCl. Ainda, o aumento no volume $(\mathrm{mL})$ para genótipo IPR Uirapuru, em função o tempo de hidratação de 0,5 hora, nas concentrações 0,50 e 125 g.L. ${ }^{-1}$ foi de $183,82 \mathrm{~mL}, 189,02 \mathrm{~mL}$ e $196,82 \mathrm{~mL}$, respectivamente. Com relação ao tempo de hidratação de 9 horas, o aumento no volume observado em função das concentrações foi de $143,86 \mathrm{~mL}$ (concentração 0 g.L.-1), 154,46 mL (concentração 50 g. $\mathrm{L}^{-1}$ ) e $170,36 \mathrm{~mL}$ (concentração 125 g. $\mathrm{L}^{-1}$ ). Ainda, no tempo de hidratação de 18 horas, com a concentração 0 g.L. $\mathrm{L}^{-1}$ de $\mathrm{NaCl}$, o volume observado foi de $132 \mathrm{~mL}$, sendo que com a concentração 50 g.L $\mathrm{L}^{-1}$ foi observado um volume de $142,1 \mathrm{~mL}$, enquanto que com a concentração 125 g. $\mathrm{L}^{-1}$ foi observado um aumento no volume para 157,25 mL. Do mesmo modo como ocorreu com a variável peso de grãos, o comportamento dos genótipos, nos tempos de hidratação em função das concentrações diferenciadas de $\mathrm{NaCl}$ foi similar, havendo um aumento no volume conforme o aumento das concentrações de $\mathrm{NaCl}$ e do tempo de hidratação.

Na literatura é discutido o efeito do período de hidratação ao qual os genótipos de feijão são submetidos antes do processo de hidratação, sendo denominado tal procedimento de maceração. Assim, é de entendimento geral que, conforme ocorre um aumento no tempo de hidratação, o aumento no peso dos grãos e no volume absorvido é promovido (GARCIA-VELA; STANLEY, 1989; PLHAK et al., 1989; RODRIGUES et al., 2005a). Entretanto, adicionando concentrações de $\mathrm{NaCl}$, ficaram evidenciadas mudanças de comportamento, ou seja, houve uma redução no peso dos grãos ao final do tempo de hidratação, 
Tabela 3. Desdobramento dos graus de liberdade através do efeito simples (slice), fixando o nível de um fator e variando os níveis do outro (genótipo, tempo de hidratação - fixados - e concentrações de $\mathrm{NaCl}$ - variando) e determinação do grau do polinômio para a interação genótipo versus concentrações de sal (g. $\left.\mathrm{L}^{-1}\right)$ versus tempo de hidratação (horas) $\left(\mathrm{G}^{\star} \mathrm{S}^{\star} \mathrm{H}\right)$ para os genótipos e os tempos de hidratação, variando as concentrações de $\mathrm{NaCl}$.

\begin{tabular}{|c|c|c|c|c|c|c|}
\hline & \multirow[t]{2}{*}{ Genótipos } & \multirow{2}{*}{$\begin{array}{l}\text { Tempo de hidratação } \\
\text { (horas) }\end{array}$} & \multirow[t]{2}{*}{ G.L. } & \multicolumn{3}{|c|}{ Q.M. } \\
\hline & & & & $\begin{array}{l}\text { Peso } \\
(\mathrm{g})\end{array}$ & $\begin{array}{l}\text { Volume } \\
(\mathrm{mL})\end{array}$ & $\begin{array}{l}\text { Tempo de cocção } \\
\text { (minutos) }\end{array}$ \\
\hline \multicolumn{2}{|r|}{ Pérola } & 0,5 & 2 & 2,01 & 24,50 & 33,16 \\
\hline \multicolumn{2}{|r|}{ Pérola } & 9 & 2 & $34,81^{*}$ & $90,50^{*}$ & 7,16 \\
\hline \multicolumn{2}{|r|}{ Pérola } & 18 & 2 & $261,33^{*}$ & $586,16^{*}$ & 944,66 \\
\hline \multicolumn{2}{|r|}{ IPR Uirapuru } & 0,5 & 2 & $95,01^{*}$ & $364,66^{*}$ & 468,50 \\
\hline \multicolumn{2}{|r|}{ IPR Uirapuru } & 9 & 2 & $74,29^{*}$ & $221,16^{*}$ & 73,50 \\
\hline \multicolumn{2}{|r|}{ IPR Uirapuru } & 18 & 2 & $106,63^{\star}$ & $344,00^{*}$ & 116,66 \\
\hline $\mathrm{L}$ & Pérola & 0,5 & 1 & ns & ns & ns \\
\hline $\mathrm{Q}$ & Pérola & 0,5 & 1 & ns & ns & ns \\
\hline $\mathrm{L}$ & Pérola & 9 & 1 & $Y=97,85-0,90 x^{*}$ & $Y=140+1.36 x^{*}$ & ns \\
\hline Q & Pérola & 9 & & ns & ns & ns \\
\hline $\mathrm{L}$ & Pérola & 18 & 1 & $\mathrm{Y}=95,85-0,47 \mathrm{x}^{\star}$ & $\mathrm{Y}=132+0.83 \mathrm{x}^{*}$ & ns \\
\hline $\mathrm{Q}$ & Pérola & 18 & 1 & ns & ns & ns \\
\hline $\mathrm{L}$ & IPR Uirapuru & 0,5 & 1 & $\mathrm{Y}=62,93-0,33 \mathrm{x}^{*}$ & $\mathrm{Y}=184+0.52 \mathrm{x}^{*}$ & ns \\
\hline Q & IPR Uirapuru & 0,5 & 1 & ns & ns & ns \\
\hline $\mathrm{L}$ & IPR Uirapuru & 9 & 1 & $Y=93,75-0,52 x^{*}$ & $\mathrm{Y}=144+1.06 \mathrm{x}^{*}$ & ns \\
\hline Q & IPR Uirapuru & 9 & 1 & ns & ns & ns \\
\hline $\mathrm{L}$ & IPR Uirapuru & 18 & 1 & $Y=97,17-0,55 x^{*}$ & $\mathrm{Y}=132+1.01 \mathrm{x}^{*}$ & $\mathrm{~ns}$ \\
\hline $\mathrm{Q}$ & IPR Uirapuru & 18 & 1 & ns & ns & ns \\
\hline
\end{tabular}

*Significativo ao nível de 5\% de probabilidade de erro pelo teste $\mathrm{F} ; \mathrm{L}$ = grau do polinômio linear; e $\mathrm{Q}$ = grau do polinômio quadrático.

apesar do volume absorvido aumentar. Tal fato pode ser justificado por mudanças que ocorrem no nível de cotilédones, em que a capacidade de absorção de água é reduzida. Liu; Phillips e McWatters (1993) relatam a possibilidade de alterações em níveis moleculares, como por exemplo, a movimentação de cátions $\left(\mathrm{Na}^{+}\right.$, $\mathrm{K}^{+}$) pelo $\mathrm{Ca} 2^{+}$. O sódio é empregado para reduzir o tempo de cocção, quebrando as ligações de pectato de cálcio e magnésio do tegumento e facilitando a absorção de água (MATTSON et al., 1950). Uma das possibilidades para a redução no tempo de cocção ou mudanças no peso de grãos e volume absorvido, pode ser devido a alterações no $\mathrm{pH}$, como consequência da adição de $\mathrm{NaCl}$. No entanto, são necessários novos experimentos no sentido de identificar quais as causas/relações do acréscimo de $\mathrm{NaCl}$ com mudanças no nível molecular.

Para a variável tempo de cocção, tanto o efeito da hidratação ao longo do tempo, quanto as diferentes concentrações de $\mathrm{NaCl}$, propiciaram alterações nos grãos (Figura 2).

Assim sendo, na medida em que se aumentou o tempo de hidratação, houve uma redução no tempo de cocção, até o limite máximo de 12,5 horas (Figura 2a). A partir desse tempo, houve um acréscimo no tempo de cocção, deste modo pode ser evidenciado que esse é o tempo necessário para a máxima hidratação dos grãos. Resultados similares foram encontrados por Rodrigues et al. (2005b), nos quais determinaram que o tempo de cocção é reduzido conforme o aumento no tempo de permanência dos grãos em embebição até as 12,49 horas.
Deste modo, a hidratação de sementes de feijão promove uma redução no tempo de cocção, entretanto, deve ser destacado que, após um determinado período, há certa estabilidade, não sendo significativo o efeito da hidratação para o tempo de cocção.

Do mesmo modo, o aumento nas concentrações de $\mathrm{NaCl}$ propiciaram uma diminuição no tempo de cocção, até o limite máximo de 56,50 g.L.-1 (Figura 2b). Após essa concentração, um aumento gradativo no tempo de cocção é observado, superando até mesmo a não utilização de doses de $\mathrm{NaCl}$. Onwuka e Okala (2003) verificaram que a adição de sais, como o $\mathrm{NaCl}$, em diferentes concentrações promoveram redução no tempo de cocção em legumes. Para Paredez-Lópes et al. (1991), a redução no tempo de cocção a partir de doses de sal pode constituir a base química para a produção de tecnologias que podem ser utilizadas em larga escala pela indústria, principalmente para grãos que são armazenados por um longo período de tempo. Onwuka e Okala (2003) comentam que os resultados obtidos em seus experimentos, ou seja, uma redução no tempo de cocção em legumes a partir de adição de sais, pode ser utilizada pela indústria alimentícia, destacando ainda a importância na economia de energia.

A análise de correlação fenotípica entre as variáveis peso, volume e tempo de cocção estão representadas na Tabela 4. A partir dos resultados ficou evidenciada a presença de correlação significativa entre todas as variáveis $(\mathrm{p}=0,05)$. Assim, há uma correlação negativa e significativa entre o peso e o volume em 
CV Pérola

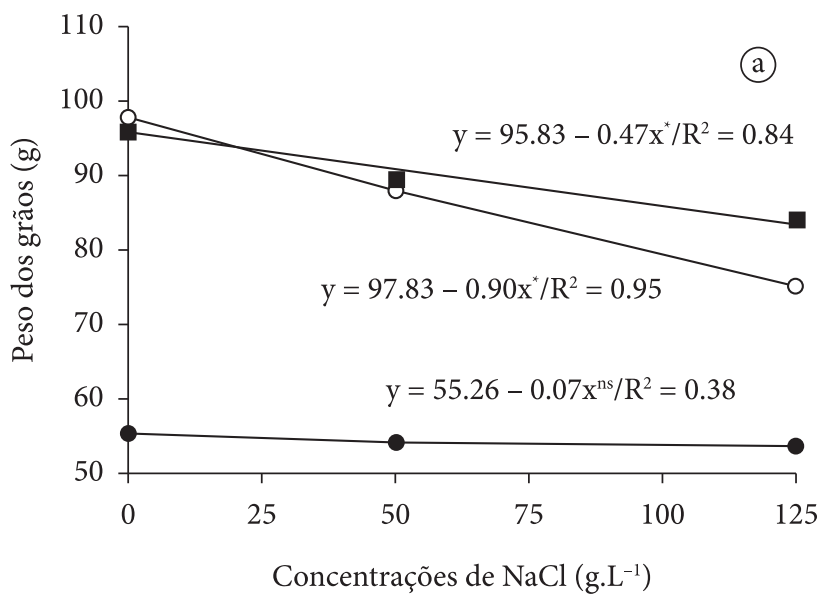

CV IPR Uirapuru

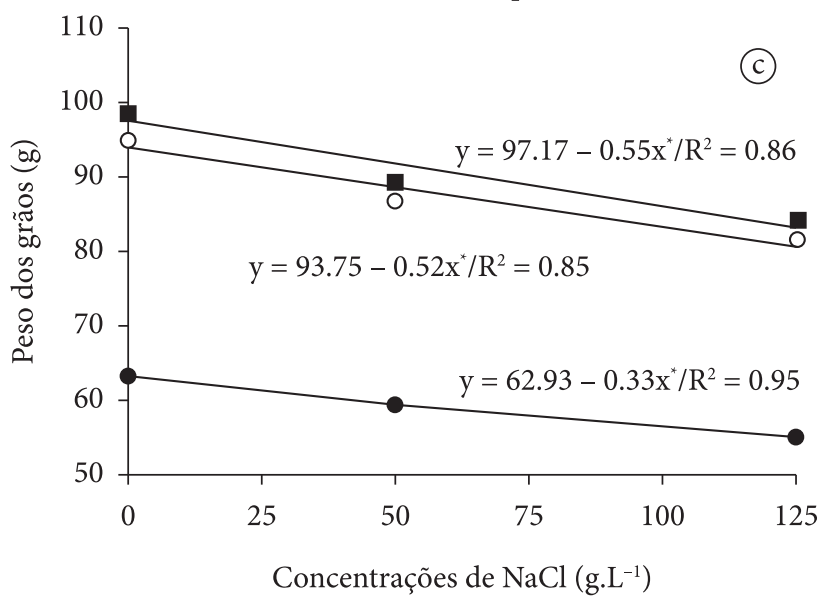

CV Pérola

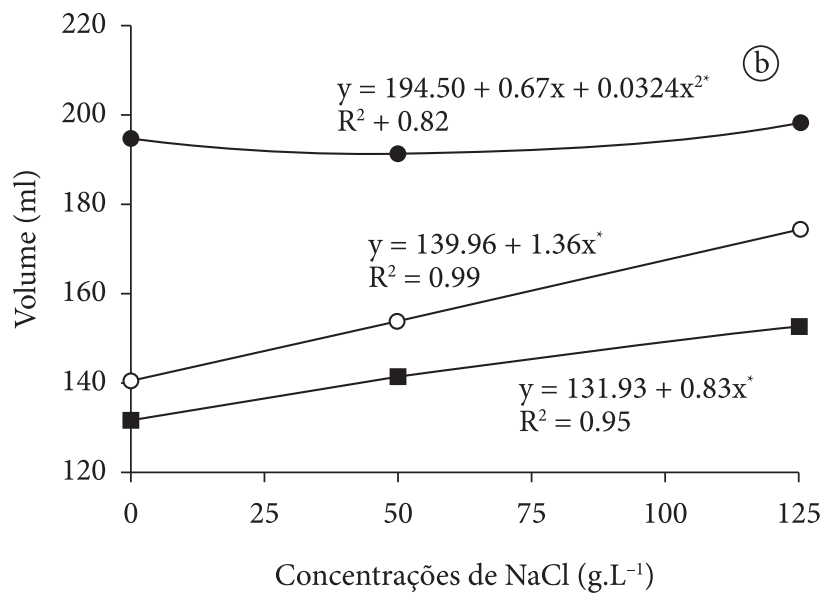

CV IPR Uirapuru

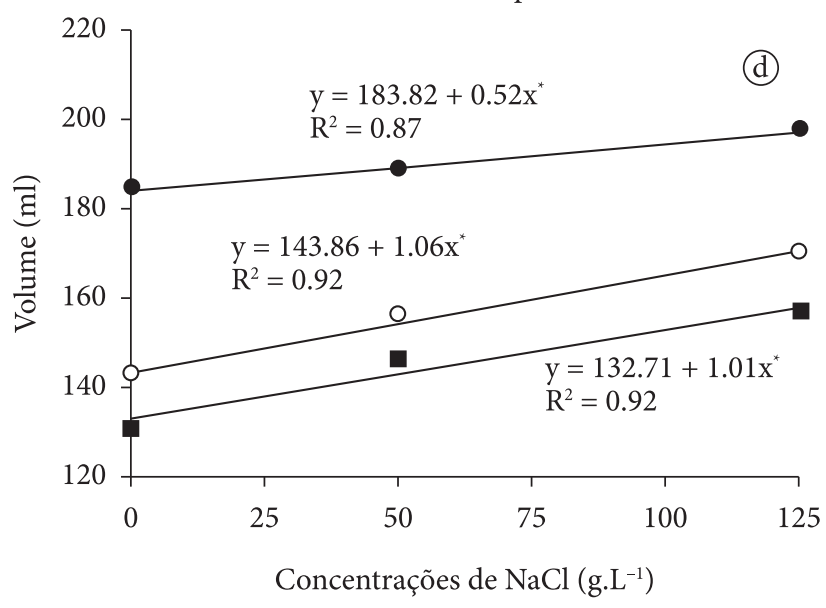

- 0,5 Horas de hidratação $\bigcirc 9$ Horas de hidratação

18 Horas de hidratação

Figura 1. Peso $(\mathrm{g})(\mathrm{a}, \mathrm{b})$ e volume $(\mathrm{mL})(\mathrm{c}, \mathrm{d})$ de grãos embebidos em água durante diferentes tempos $(0,5,9$ e 18 horas $)$ para duas cultivares comerciais de feijão (Pérola e IPR Uirapuru) em função de concentrações de $\mathrm{NaCl}$.

97\%, ou seja, na medida em que os grãos são hidratados, o peso deles aumenta e o volume total diminui. Do mesmo modo, há uma existência de correlação negativa e significativa entre a variável peso e tempo de cocção em 68\%. De modo contrário, a correlação entre o tempo de cocção e o volume foi positiva significativa em $65 \%$.

Tais correlações fenotípicas explicam a redução no tempo de cocção na medida em que se aumentam o tempo de hidratação, uma vez que grãos com maiores tempos de hidratação aumentam o seu peso final e diminuem o volume final num determinado recipiente. Rodrigues et al. (2005a) obtiveram resultados similares, concluindo que, na medida em que ocorreu incremento na percentagem de absorção de água, o tempo de cozimento foi reduzido. Do mesmo modo, tal abordagem pode ser importante em programas de melhoramento, sugerindo que o melhorista pode selecionar linhagens com menores tempos de cocção a partir de um teste prévio de hidratação, devido à existência de uma correlação negativa e significativa entre absorção de água e tempo de cocção. Rodrigues et al. (2005a) sugeriram o emprego do teste da capacidade de absorção da água pelos grãos, como indicativo de linhagens com características de qualidade de grãos para o cozimento, tais como cozimento rápido, alta percentagem de grãos normais e mínima percentagem de grãos duros. No entanto, Rodrigues et al. (2005b) ressalva que a utilização do teste de absorção de água como indicativo do tempo de cozimento deve ser melhor avaliada em programas de melhoramento, devido à presença da interação genótipo $\mathrm{x}$ ambiente para essas características.

Mediante os aspectos supracitados, é necessária a investigação dos efeitos positivos resultantes da adição de sal $(\mathrm{NaCl})$ para o caráter tempo de cocção em feijão, no sentido de viabilizar a cultura, tanto para o consumidor, quanto para a indústria, sendo que a adição de concentrações específicas de sal $(\mathrm{NaCl})$ propicia uma redução significativa no tempo de cocção. 

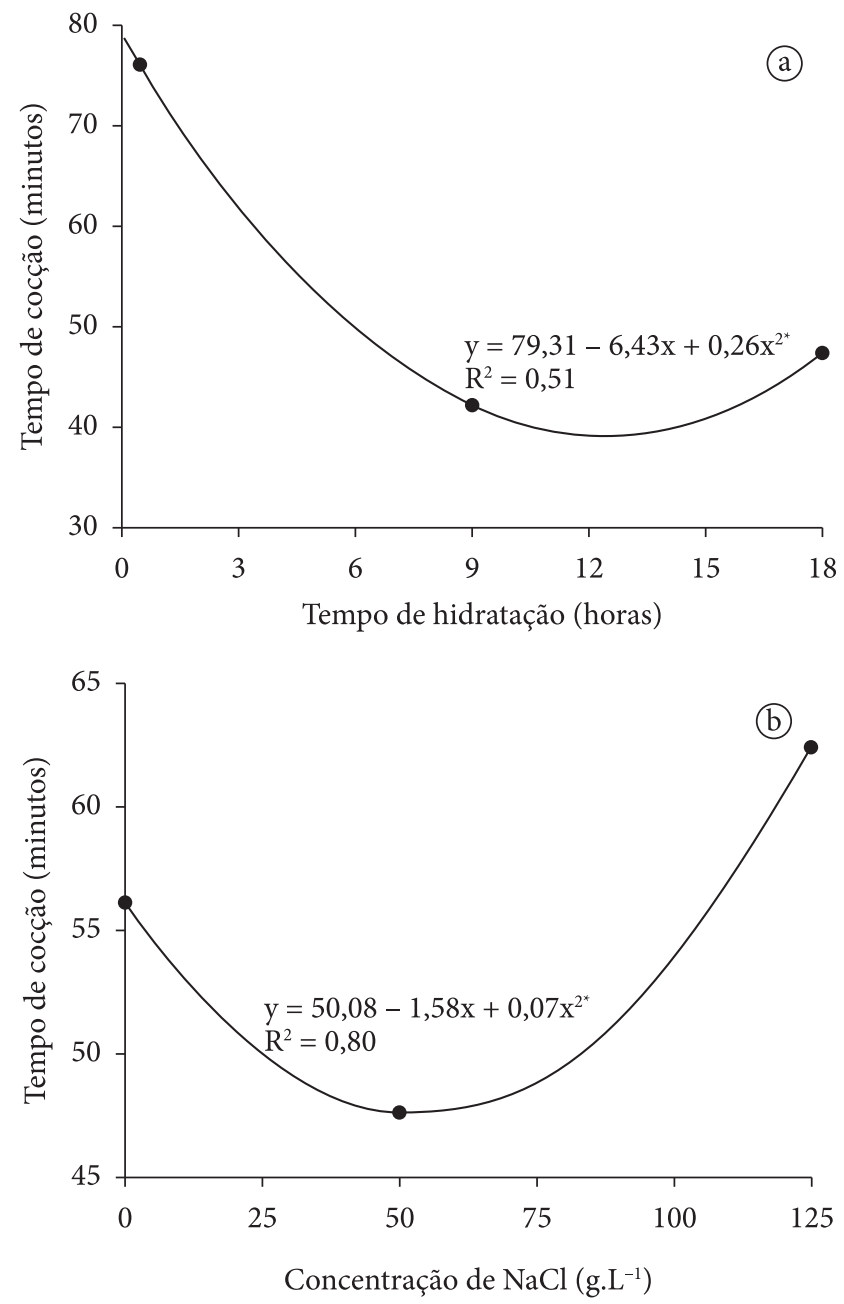

Figura 2. Variável tempo de cocção em grãos de feijão de duas cultivares comercias (Pérola e IPR Uirapuru) em função do tempo de hidratação dos grãos (2a) e concentrações de $\mathrm{NaCl}(2 \mathrm{~b})$.

Tabela 4. Correlação fenotípica de Pearson entre os caracteres peso de grãos (g), volume (mL) e tempo de cocção (minutos), obtidos a partir de dois genótipos de feijão (Pérola e Uirapuru), três tempos de hidratação $\left(0,5,9\right.$ e 18 horas) e três concentrações de sal $\left(0,50\right.$ e 125 g.L $\left.L^{-1}\right)$.

\begin{tabular}{lccc}
\hline & Peso & Volume & Cocção \\
\hline Peso & 1,000 & $-0,97^{*}$ & $-0,68^{*}$ \\
Volume & & 1,000 & $0,65^{*}$ \\
Cocção & & & 1,000 \\
\hline
\end{tabular}

'Significativo ao nível de 5\% de probabilidade de erro pelo teste $\mathrm{F}$.

\section{Conclusões}

A redução no tempo de cocção é promovida pela adição de concentrações de $\mathrm{NaCl}$, sendo o ponto máximo de 56,50 g. $\mathrm{L}^{-1}$. Concentrações maiores do que $56,50 \mathrm{~g} . \mathrm{L}^{-1}$ promovem o aumento no tempo de cocção.
A hidratação dos grãos de feijão propiciou a redução no tempo de cocção, sendo necessárias 12,5 horas para a máxima hidratação.

A adição de $\mathrm{NaCl}$ alterou o peso de grãos ao final do período de hidratação, reduzindo-o linearmente com o aumento das concentrações, sendo necessários maiores estudos para evidenciar as mudanças promovidas ao nível molecular.

\section{Agradecimentos}

Agradecemos à UDESC, UFSC, CAPES, CNPq e FAPESC a concessão de bolsa e apoio financeiro.

\section{Referências bibliográficas}

BERTOLDO, J. G. et al. Problemas relacionados com o uso de testes de comparação de médias em artigos científicos. Biotemas, v. 21, n. 2, p. 145-153, 2008.

FERREIRA, C. M.; DEL PELOSO, M. J.; FARIA, L. C. Feijão na economia nacional. Santo Antônio de Goiás: Embrapa Arroz e Feijão, 2002. 47 p. (Documentos, 135).

GARCIA, E.; LAJOLO, F. M. Starch alterations in hard-to cook beans (Phaseolus vulgaris). Journal Agricultural Food Chemistry, v. 42, p. 612, 1994.

GARCIA-VELA, L. A.; STANLEY, D. W. Water-holding capacity in hard-to-cook bean (Phaseolus vulgaris L.): effect of $\mathrm{pH}$ and ionic strength. Journal of Food Science, v. 54, n. 4, p. 1080-1081, 1989.

IALCIM, C.; ERSAN, K. Effect of location and soaking treatments on the cooking quality of some chickpea breeding lines. International Journal of Food Science and Technology, v. 38, n. 1, p. 751-757, 2003.

LIU, K.; PHILLIPS, R. D.; MCWATTERS, K. H. Mechanism of pectin changes during soaking and heating as related to hard-to-cook defect in cowpeas. Journal of Agriculture and Food Chemistry, v. 41, n. 1, p. 1476-1480, 1993.

MATTSON, S.; AKERBERG, E.; ERIKSSONN, E. Factors determining the composition of cookability of peas. Acta Agriculturae Scandinavica, v. 1, n. 1, p. 41-49, 1950.

ONWUKA, U. N.; OKALA, O. Effects of selected salts on the cooking time, protein content and sensory properties of African yam beans and cowpeas. Food Service Technology, v. 3, n. 1, p. 3-7, 2003.

PLHAK, L.C. et al. Comparison of methods used to characterize water imbibition in hard-to-cook beans. Journal of Food Science, v. 54, n. 2, p. 326-329, 1989.

PROCTOR, J. R.; WATTS, B. M. Development of a modified mattson bean cooker procedure base don sensory panel cookability evaluation. Canadian Institute of Food Science and Technology Journal, v. 20, n. 1, p. 9-14, 1987.

RODRIGUES, J. A. et al. Qualidade para o cozimento de grãos de feijão obtidos em diferentes épocas de semeadura. Bragantia, v. 64, n. 3, p. 369-376, 2005b.

RODRIGUES, J. et al. Correlação entre absorção de água e tempo de cozimento de cultivares de feijão. Ciência Rural, v. 35, n. 1, p. 209-214, 2005a. 